\title{
The Transmittance, Transmittance Wavefront, and Laser Induced Damage Properties of Thin Fluoride Polymer Films May Be Used as Short Pulse Laser Debris Shields
}

\author{
Shufan Chen, Chuanqun Huang, Xiaodong Jiang, Xuan Luo, Yu Fang, and Weidong Wu \\ Research Center of Laser Fusion, China Academy of Engineering Physics, Mianyang, Sichuan 621900, China \\ Correspondence should be addressed to Weidong Wu; wuweidongding@163.com
}

Received 4 February 2016; Accepted 29 March 2016

Academic Editor: Beng T. Poh

Copyright (c) 2016 Shufan Chen et al. This is an open access article distributed under the Creative Commons Attribution License, which permits unrestricted use, distribution, and reproduction in any medium, provided the original work is properly cited.

Debris mitigation which pollutes and even damages the optical elements is a major challenge for all high-peak-power lasers system. In order to solve the problem, we employed some preliminary research. In this work, first, the film optical properties of fluorinated ethylene propylene (FEP), perfluoroalkoxy copolymer (PFA), and ethane-tetrafluoroethylene copolymer (ETFE) were investigated with respect to their possible application as laser debris shields. The results indicate that three of the polymer films have high transmittance at $355 \mathrm{~nm}$, especially in FEP film, the transmittance of which at $355 \mathrm{~nm}$ is near to $94 \%$. The transmittance wavefront and the laser that induce damage of FEP film were investigated further. The result indicates that the wavefront error of FEP film (with a diameter of $90 \mathrm{~mm}$ ) is about $0.33 \lambda$. The damage test was performed by a $355 \mathrm{~nm}$ neodymium:yttrium aluminum garnet (Nd:YAG) laser with a $9.3 \mathrm{~ns}$ pulse duration, and it was found that the highest nondamage fluence for FEP film is $10.35 \mathrm{~J} / \mathrm{cm}^{2}$. Through a demonstration experiment, it was testified that the FEP film can prevent large amount of metal fractions and the FEP film can be used as the debris shields indeed.

\section{Introduction}

In inertial confinement fusion (ICF) experiments, when the target is bombarded by laser, amount of target debris will be generated. The laser target debris is consisting of a small amount of metal vapor, droplets of liquid metal, and massive solid projectiles. This debris will pollute and even damage the optical elements. To protect against these various classes of debris, a multielement approach has been adopted [13]. First, use self-closing nose cone to prevent the debris from going into the beam path; second, use a pneumatic fast valve to prevent the large and low speed fraction; third, use a thin polymer film debris shield to replace the traditional fused silica antireflection (AR) coated window to prevent almost all debris. The third method is effective, inexpensive, and convenient, and the using of polymer film can avoid the self-phase modulation, self-focusing, and beam breakup of the traditional silica window [4-6]. According to the report of Sandia [1], nitrocellulose, Mylar, and polyimide were investigated, and finally it was found that the nitrocellulose has the best properties. According to the criterion of the polymer films which begin to turn up large scale of holes, the highest nondamage fluence for nitrocellulose was $11.5 \mathrm{~J} / \mathrm{cm}^{2}$. The nitrocellulose film has been used as the short pulse laser debris shields. A $43.2 \mathrm{~cm}$ diameter pellicle is now being fabricated for first Petawatt backlighting experiments on the Z-Accelerator.

Even the researchers of Sandia have done excellent work on the polymer film debris shield, but they only care about the Z-Petawatt FOA with the working wavelength of $1054 \mathrm{~nm}$. The polymer film can be used at $1054 \mathrm{~nm}$, but it is inapplicable to National Ignition Facility (NIF) for the working wavelength of which tripled laser is about $355 \mathrm{~nm}$ and the three kinds of polymer film including nitrocellulose, Mylar, and polyimide all have obvious absorption at $355 \mathrm{~nm}$. In order to provide the available material for the future NIF, our work aims at the laser of $355 \mathrm{~nm}$ wavelength. The main difficulty is the high damage possibility of polymers at $355 \mathrm{~nm}$ wavelength. Besides, the reflection of the film and the laser transmission wavefront distortion have to 

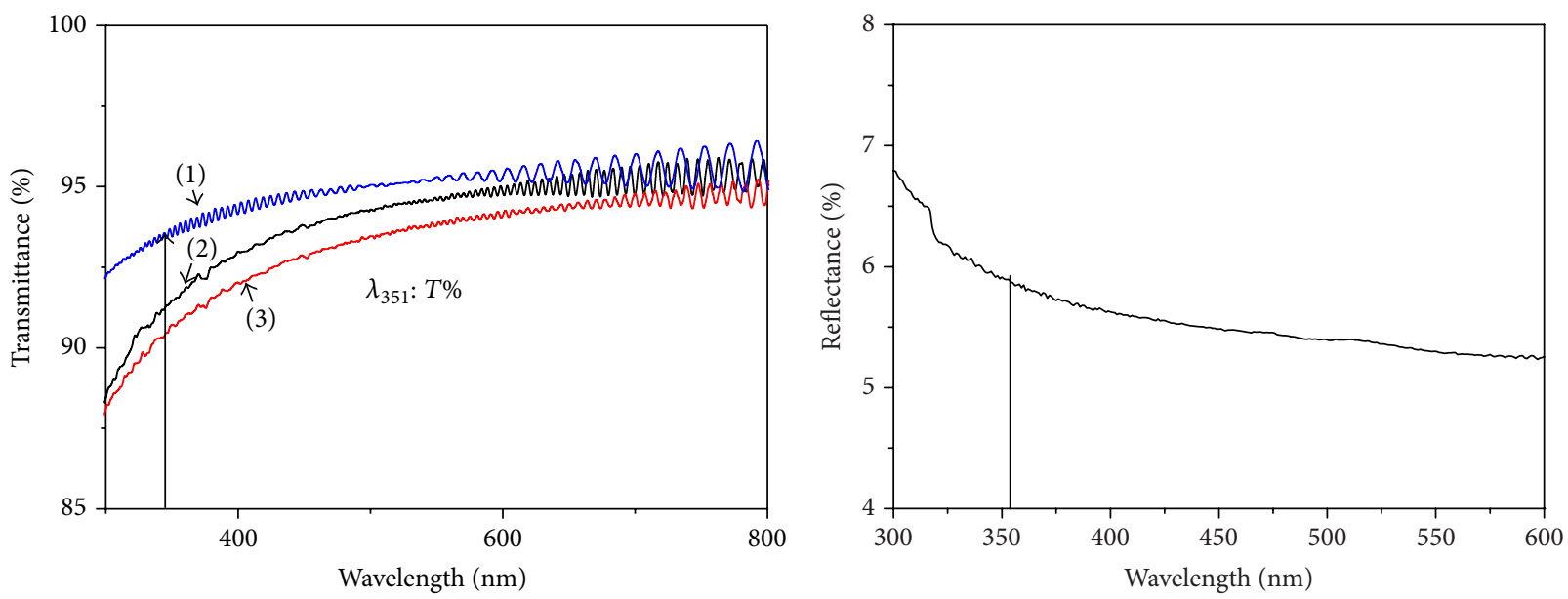

(1) FEP-93.86\%

(2) PFA- $91.54 \%$

(3) ETFE- $90.83 \%$

(a)

(b)

Figure 1: (a) Transmittance and (b) reflectance of the three kinds of fluoride polymer films range from $300 \mathrm{~nm}$ to $800 \mathrm{~nm}$.

be considered. Furthermore, the polymer film should have mechanical rigidity to withstand small debris $[1,7-10]$. Based on this, fluoride polymers were investigated with respect to their optical and spectral transmission quality, absorption, stress induced birefringence, and damage threshold [11, 12].

In our research, three kinds of fluoride polymer films including fluorinated ethylene propylene (FEP), perfluoroalkoxy copolymer (PFA), and ethane-tetrafluoroethylene copolymer (ETFE) which have superior mechanical property and low absorption at $355 \mathrm{~nm}$ were investigated. Some preliminary results were achieved.

\section{Experimental}

2.1. Sample Preparation. Three kinds of thin films (fluorinated ethylene propylene (FEP), perfluoroalkoxy copolymer (PFA), and ethane-tetrafluoroethylene copolymer (ETFE)) were ultrasonic cleaned first in alcohol and then in hexane solution; the cleaning time is about $10 \mathrm{~min}$. And then, the films were swept by high purity nitrogen gas (99.99\%). The cleaned films were fixed by an embroidery frame and were characterized.

2.2. Sample Characterization. The transmittance of films was characterized by UV-3010 spectrophotometer (Japan) at room temperature ranging within $300 \mathrm{~nm} \sim 800 \mathrm{~nm}$.

Wavefront transmission characteristics were measured using a $4^{\prime \prime}$ interferometer from $4 \mathrm{D}$-Technologies (FizCam 1500) operating at a wavelength of $632.8 \mathrm{~nm}$. The debris shield was placed between the interferometer and a reference mirror with a peak-to-valley (PV) wavefront quality $<\lambda / 20$. The wavefront upon reflection from this reference flat was measured and later subtracted from the measurement of the double pass transmission through the thin film, vertical polarization at a constant probe wavelength of $632.8 \mathrm{~nm}$.

Damage testing was performed using a Q-switched Nd:YAG laser at $355 \mathrm{~nm}$ with a $9.3 \mathrm{~ns}$ pulse duration.

\section{Result and Discussion}

3.1. UV-Vis Spectra Analysis of the Three Kinds of Fluoride Polymer Films. Figure 1(a) shows the transmittance of the three kinds of fluoride polymer films. It can be observed from Figure 1(a) that the three of the polymer films have high transmittance at $355 \mathrm{~nm}$; especially in FEP film, the transmittance at $355 \mathrm{~nm}$ is near to $94 \%$ (93.86\%). Because the transmittance of FEP film at $355 \mathrm{~nm}$ is the highest in the three kinds of fluoride polymer films, the properties of FEP film were further investigated, but no further studies have been performed on PFA and ETFE films. Figure 1(b) shows the reflectance curve of FEP film; according to the result we can get the double faced reflectance of FEP film at $355 \mathrm{~nm}$ which is about $5.85 \%$, and according to the following equations, the single face reflectance and refractive index of FEP film can be calculated:

$$
A=1-T-R
$$

where $A$ is the absorption of FEP film at $355 \mathrm{~nm} ; T$ and $R$ are the measured transmittance and reflectance of FEP film at $355 \mathrm{~nm}$.

Presuming that the single faced transmittance and reflectance of FEP film at $355 \mathrm{~nm}$ are $T_{1}$ and $R_{1}$, respectively, (3) can be obtained. Quadratic term was omitted; (4) and (5) can be obtained:

$$
T_{1}=1-R_{1}
$$




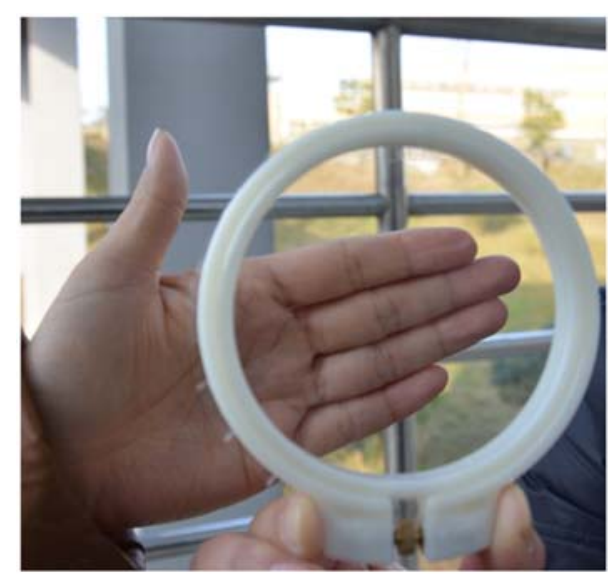

FIGURE 2: Photograph of polymer FEP film with the diameter of $90 \mathrm{~mm}$.

$$
\begin{aligned}
T & =\frac{T_{1}^{2}(1-A)}{\left(1-R_{1}^{2}(1-2 A)\right)}, \\
T & =\left(1-R_{1}\right)^{2}(1-A), \\
R_{1} & =1-\left(\frac{T}{(1-A)}\right)^{0.5} .
\end{aligned}
$$

Finally, the single faced reflectance $R_{1}$ of FEP film was worked out as $3.004 \%$.

According to the relation between reflectance and refractive index (6), the refractive index 1.419 of FEP film at $355 \mathrm{~nm}$ was obtained:

$$
R_{1}=\frac{(n-1)^{2}}{(n+1)^{2}},
$$

where $n$ is the refractive index of FEP film at $355 \mathrm{~nm}$; 1 is the refractive index of atmosphere.

According to the above analysis, transmittance of FEP film at $355 \mathrm{~nm}$ is $93.86 \%$, and the total transmittance loss of $6.14 \%$ consists of $5.85 \%$ double faced reflectance and $0.29 \%$ absorption of polymer film along with the surface scattering. The result indicates that, through decreasing the reflectivity of polymer FEP film, the transmittance of the film can be obviously improved. The FEP film was prepared to optical element; the morphology of FEP film was shown in Figure 2.

3.2. Results of Wavefront Transmission Characteristics. Figure 3 shows the wavefront error caused by the double pass transmission of a $90 \mathrm{~mm}$ diameter laser beam through FEP film. The measured wavefront distortion (PV) is $0.33 \lambda$; the root mean square (RMS) deviation from a perfectly flat wavefront is $0.068 \lambda$.

3.3. Laser Induced Damage Testing. The laser induced damage was deeply investigated. The damage test was performed with a $355 \mathrm{~nm}$ neodymium:yttrium aluminum garnet (Nd:YAG) laser with a 9.3 ns pulse duration. We found that the laser induced damage of the fluoride polymer film can be divided into three processes (Figure 4). First process: when the laser energy density is lower than certain value, the film has no change. Second process: when the laser energy density increased to certain range, the structure of polymer film begins to change and the glow spots turn up, but no obvious holes can be observed (some small pinpoint may be observed with microscopy). Third process: when the laser energy further increased to certain value, there are obvious holes that can be observed on the film. We define the three processes as no-change process, property changing process, and obvious holes turning up process. The testing results of the highest laser fluence of each process are shown in Figure 5.

According to the results of Figure 5, it can be calculated that the highest laser fluence of first process is $3.35 \mathrm{~J} / \mathrm{cm}^{2}$, and the highest laser fluence of second process is $10.35 \mathrm{~J} / \mathrm{cm}^{2}$. It means that when the laser energy density is lower than $3.35 \mathrm{~J} / \mathrm{cm}^{2}$, the film has no changes after the laser breaks through; when the laser energy density is within $3.35 \mathrm{~J} / \mathrm{cm}^{2} \sim$ $10.35 \mathrm{~J} / \mathrm{cm}^{2}$, the structure of polymer film will change, but no obvious holes can be observed; when the laser energy density is higher than $10.35 \mathrm{~J} / \mathrm{cm}^{2}$, obvious holes will turn up on the film.

We are afraid that the structure change of film will influence the transmission of laser, so we investigated the dynamic transmittance of laser with different energy density through the film during the three processes. We used the laser with different energy density $\left(I_{0}\right)$ breaking through the film and measured the energy density $\left(I_{1}\right)$ of the laser after it gets through the film at the same time; the result of $I_{0}$ divided by $I_{1}$ is the dynamic transmittance of film. The result indicates that the dynamic transmittances of the three processes all are about $89 \%$. It testifies that when the laser energy density is higher than $3.35 \mathrm{~J} / \mathrm{cm}^{2}$, even the structure of polymer film changes, but before that, the laser has got through the polymer film, so the structure change has no influence on the laser transmission.

According to Sandia's report [1], the main purpose of the debris shield is to prevent debris vapor and fractions from being deposited on the final focusing parabola: in that respect one can tolerate small scale holes. Therefore, when the laser energy density is within $3.35 \mathrm{~J} / \mathrm{cm}^{2} \sim 10.35 \mathrm{~J} / \mathrm{cm}^{2}$, even if there are some small pinpoints that turn up on the film (property changing process), the FEP film still can be used as the debris shield also. In other words, the highest nondamage fluence for FEP film is $10.35 \mathrm{~J} / \mathrm{cm}^{2}$.

The microscopic-morphologies of laser induced damage on FEP film were characterized and shown in Figure 6. It can be observed from Figure 6(a) that when the laser energy density is within $3.35 \mathrm{~J} / \mathrm{cm}^{2} \sim 10.35 \mathrm{~J} / \mathrm{cm}^{2}$, the film becomes blushing after the laser passes through, and some small pinpoints can be observed under the microscope. From Figure 6(b), it can be observed that when the laser energy density is higher than $10.35 \mathrm{~J} / \mathrm{cm}^{2}$, obvious holes can be observed on the laser damaged film. Under this condition, the films cannot be used as debris shields.

3.4. Demonstration Experiment of the FEP Film Was Used as the Debris Shield. In order to verify whether the polymer film 


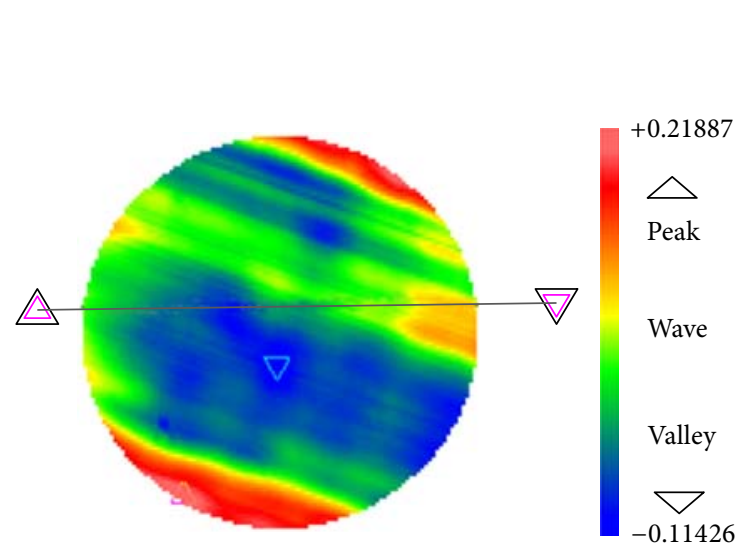

(a)

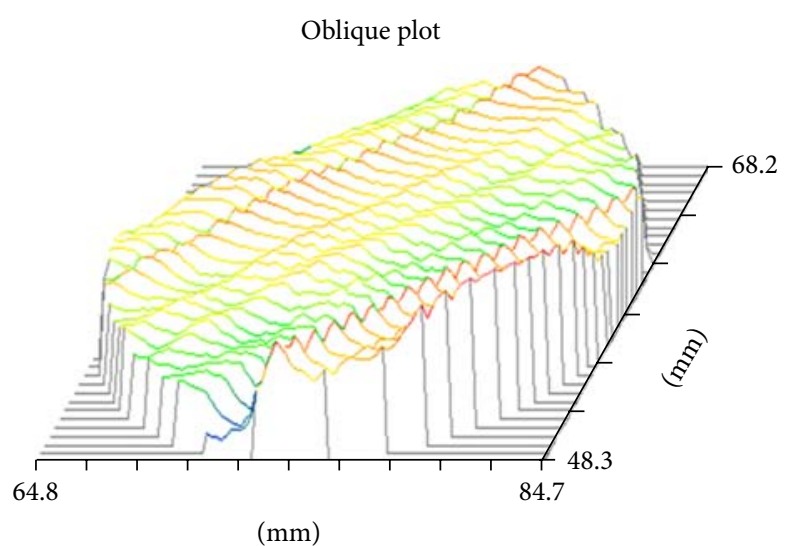

(b)

FIGURE 3: Wavefront distortion after a double pass through FEP film: (a) the aerial view and (b) the three-dimensional graph.

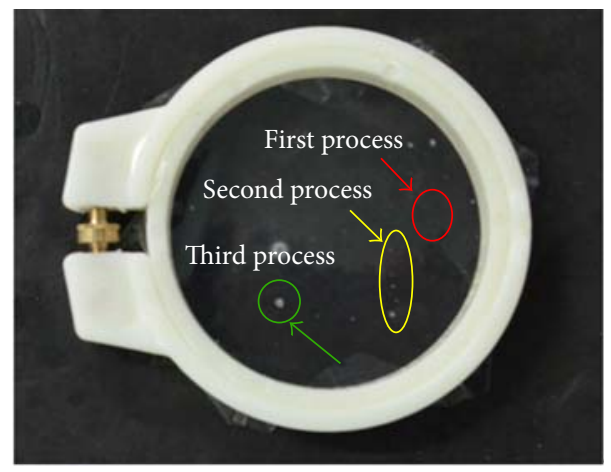

FIGURE 4: Morphologies of laser induced damage on FEP film.

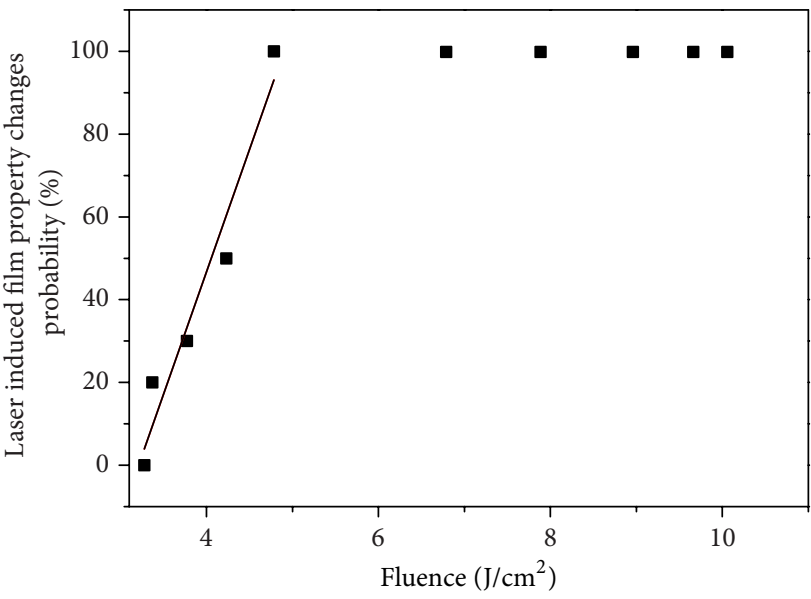

(a)

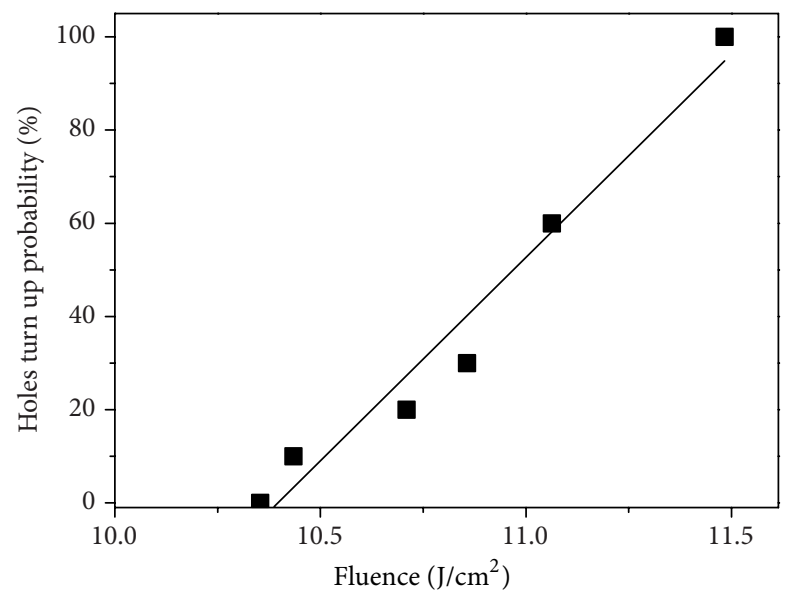

(b)

FIGURE 5: Damage test results for FEP film: (a) property changes probability (second process) and (b) holes turn up probability (third process).

can prevent the debris, we had performed a demonstration experiment (Figure 7). Same as the damage test, the experiment was performed with a $355 \mathrm{~nm}$ neodymium:yttrium aluminum garnet (Nd:YAG) laser with a $9.3 \mathrm{~ns}$ pulse duration, the laser energy is $8.23 \mathrm{~J} / \mathrm{cm}^{2}$, and the diameter of the focal spot is about $2 \mathrm{~mm}$. The FEP film was put into the laser beam path before a steel panel, and the distance of FEP film to steel panel is about $10 \mathrm{~cm}$; then the laser was used to bombard the steel panel and the distance between focal spot and steel panel is about $50 \mathrm{~cm}$. Finally, the FEP film was observed by microscope and the result indicates that a large amount of steel fractions was observed on the FEP film (Figure 8) and 


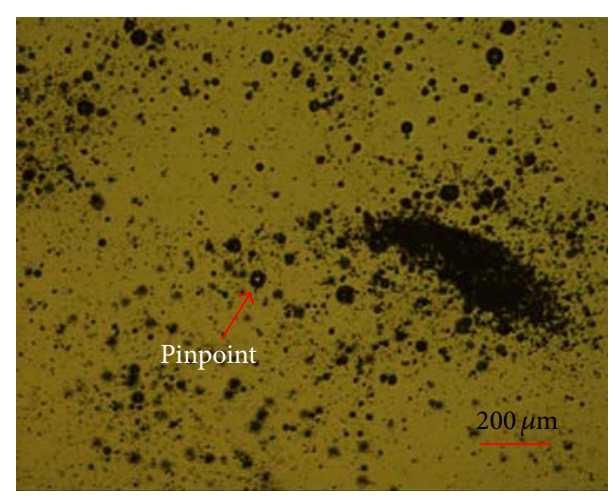

(a)

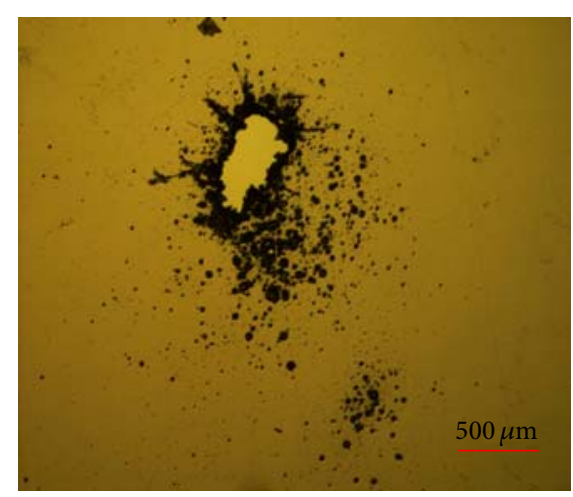

(b)

FiguRE 6: Microscopic-morphologies of laser induced damage: (a) the laser energy density within $3.35 \mathrm{~J} / \mathrm{cm}^{2} \sim 10.35 \mathrm{~J} / \mathrm{cm}^{2}$ (second process) and (b) the laser energy density higher than $10.35 \mathrm{~J} / \mathrm{cm}^{2}$ (third process).

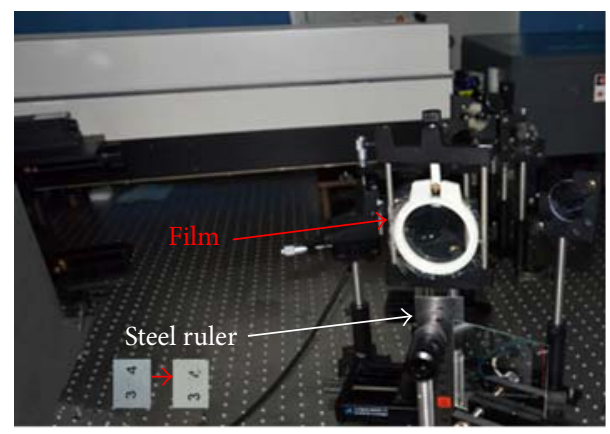

FIGURE 7: FEP film was used as debris shields.

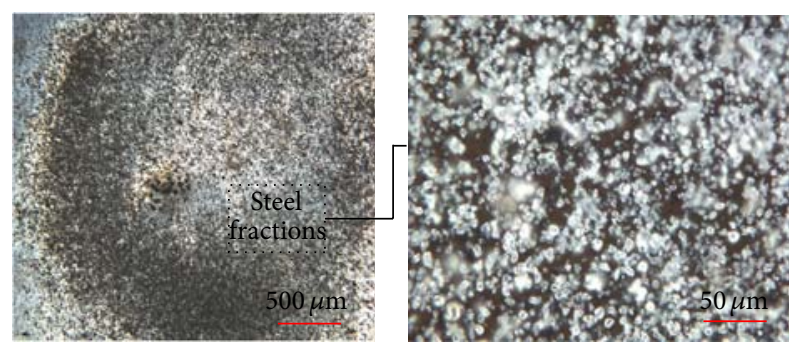

FIGURE 8: Microscopic-morphologies of FEP film after it was used as debris shields.

demonstrates that the FEP film can prevent the debris from getting into the laser path indeed.

\section{Conclusions}

Optical properties of three kinds of fluoride polymer films FEP, PFA, and ETFE and the possibility of fluoride polymer film used as the debris shields were investigated. The results indicate that three of the polymer films have high transmittance at $355 \mathrm{~nm}$, especially in FEP film, the transmittance of which at $355 \mathrm{~nm}$ is near to $94 \%$. The transmittance loss of FEP film is mainly coming from the double faced reflectance, and through decreasing the reflectivity, the transmittance of this polymer film can be obviously enhanced. The laser induced damage on the fluoride polymer film can be divided into three processes, and the highest nondamage fluence for FEP film is $10.35 \mathrm{~J} / \mathrm{cm}^{2}$. Through a demonstration experiment, we found that the FEP film can prevent large amount of metal fractions, it proves that the film can prevent the debris from getting into the laser pathway, and it can be used as the debris shields indeed.

\section{Competing Interests}

The authors Shufan Chen, Chuanqun Huang, Xiaodong Jiang, Xuan Luo, Yu Fang, and Weidong Wu declare that there is no conflict of interests regarding the publication of this paper.

\section{Acknowledgments}

This work was financially supported by the Development Foundation of China Academy of Engineering Physics (no. 2013A0302016) and the National Foundation of China (Grant no. 11174258).

\section{References}

[1] J. Schwarz, P. Rambo, M. Geissel, D. Headley, M. Ramsey, and B. Atherton, "Studies on thin films as short pulse laser debris shields," in Laser-Induced Damage in Optical Materials, vol. 6720 of Proceedings of SPIE, 10 pages, December 2007.

[2] S. H. Fan, H. B. He, Z. X. Fan, J. D. Shao, and Y. A. Zhao, "Theory and experiment of surface thermal lens technique used in absorption measurement of thin films," Acta Physica Sinica, vol. 54, no. 12, pp. 5774-5777, 2005.

[3] Y. Zheng, Z. C. Liu, P. Ma, S. L. Chen, and Q. H. Zhang, "Laser conditioning technique of mid-size laser spot," High Power Laser and Particle Beams, vol. 25, no. 12, pp. 3180-3184, 2013.

[4] R. Spielman, C. Deeney, G. Chandler et al., "Tungsten wirearray Z-pinch experiments at 200 TW and 2 MJ," in Proceedings of the 39th Annual Meeting of the Division of Plasma Physics of the American Physical Society, pp. 2105-2111, Pittsburgh, Pa, USA, November 1997. 
[5] P. K. Rambo, I. C. Smith, J. L. Porter Jr. et al., "Z-Beamlet: a multikilojoule, terawatt-class laser system," Applied Optics, vol. 44, no. 12, pp. 2421-2430, 2005.

[6] G. Bennett, O. Landen, R. Adams et al., "X-ray imaging techniques on Z using the Z-Beamlet laser," Review of Scientific Instruments, vol. 72, no. 1, p. 657, 2001.

[7] H. Y. Hu, Z. X. Fan, and Q. Zhao, "Measuring weak absorptance of thin film coatings by surface thermal lensing technique," Acta Optica Sinica, vol. 21, no. 2, pp. 150-154, 2001.

[8] W. H. Jiang and H. G. Li, "Hartmann-Shack wavefront sensing and wavefront control algorithm," in Adaptive Optics and Optical Structures, vol. 1271 of Proceedings of SPIE, p. 82, The Hague, Netherlands, March 1990.

[9] J. F. Power, "Pulsed mode thermal lens effect detection in the near field via thermally induced probe beam spatial phase modulation: a theory," Applied Optics, vol. 29, no. 1, pp. 52-63, 1990.

[10] S. Y. Wang, Y. M. Lu, X. Liu et al., "Preparation and properties of boron carbide film using pulsed laser deposition," High Power Laser and Particle Beams, vol. 25, no. 4, pp. 895-897, 2013.

[11] E. Leivo, T. Wilenius, T. Kinos, P. Vuoristo, and T. Mäntylä, "Properties of thermally sprayed fluoropolymer PVDF, ECTFE, PFA and FEP coatings," Progress in Organic Coatings, vol. 49, no. 1, pp. 69-73, 2004.

[12] T. Takayanagi and M. Yamabe, "Progress of fluoropolymers on coating applications: development of mineral spirit soluble polymer and aqueous dispersion," Progress in Organic Coatings, vol. 40 , no. $1-4$, pp. $185-190,2000$. 

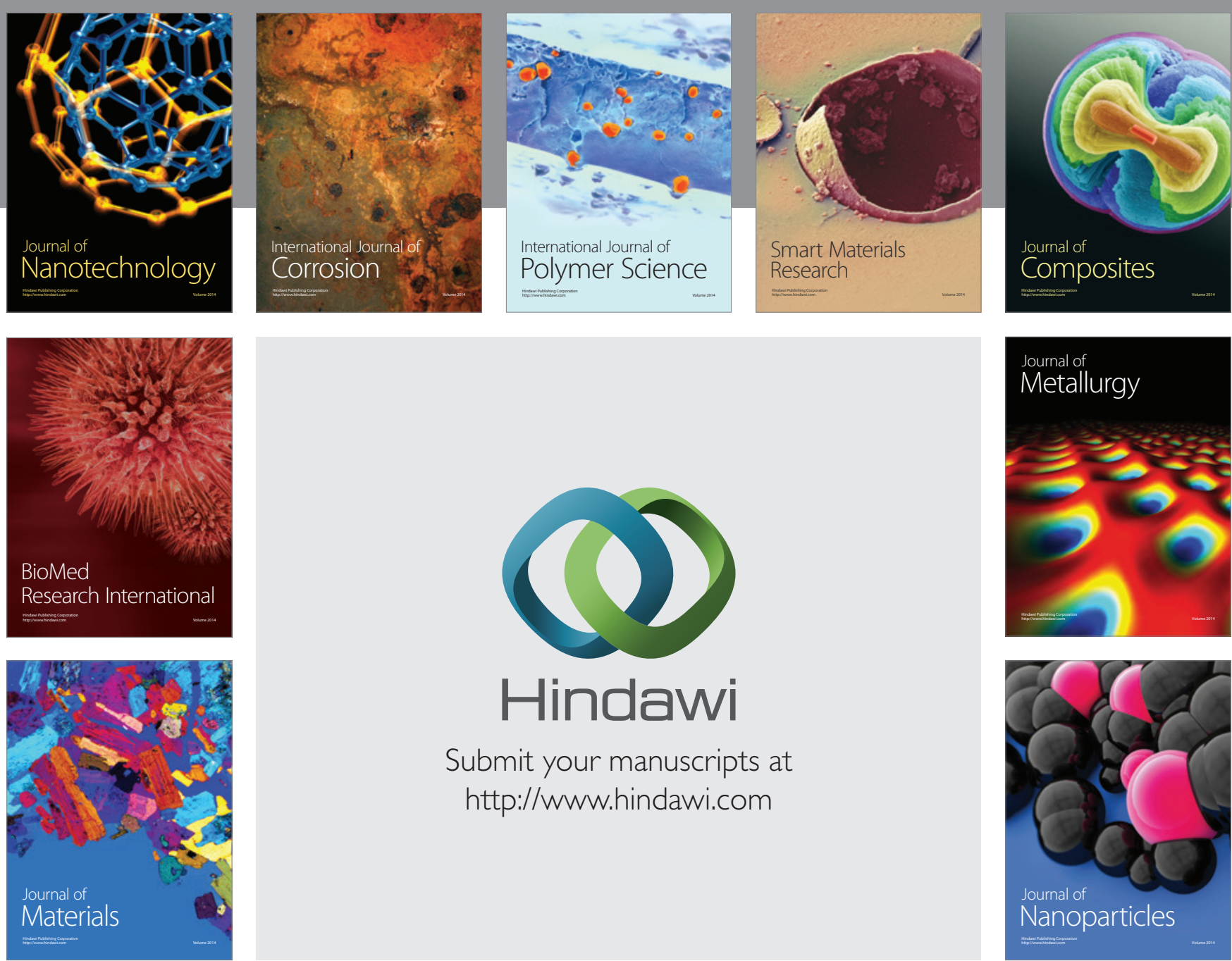

\section{Hindawi}

Submit your manuscripts at

http://www.hindawi.com

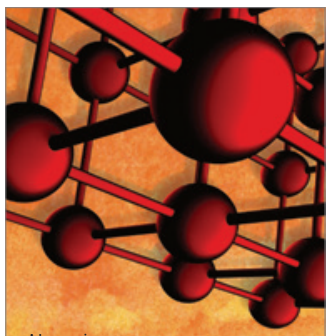

Materials Science and Engineering
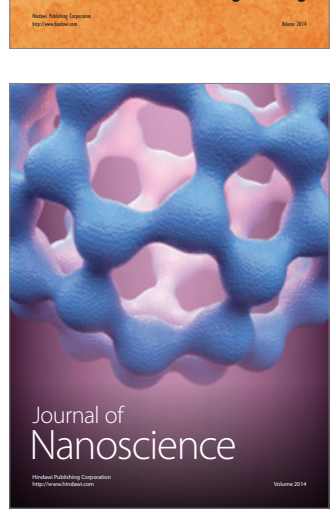
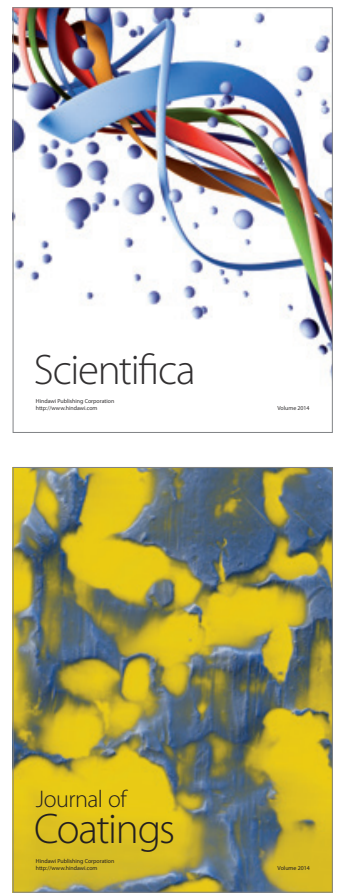
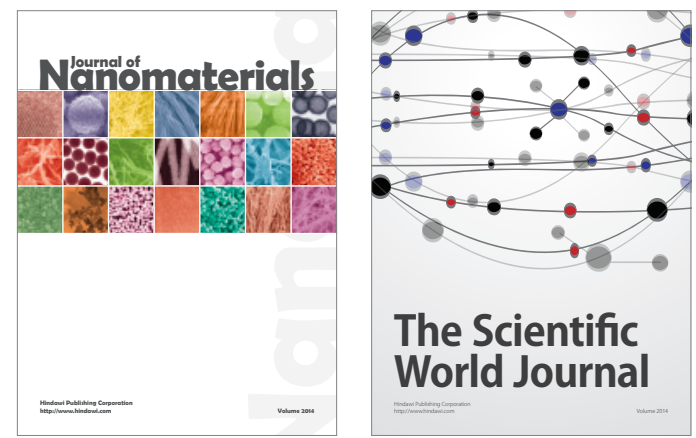

The Scientific World Journal
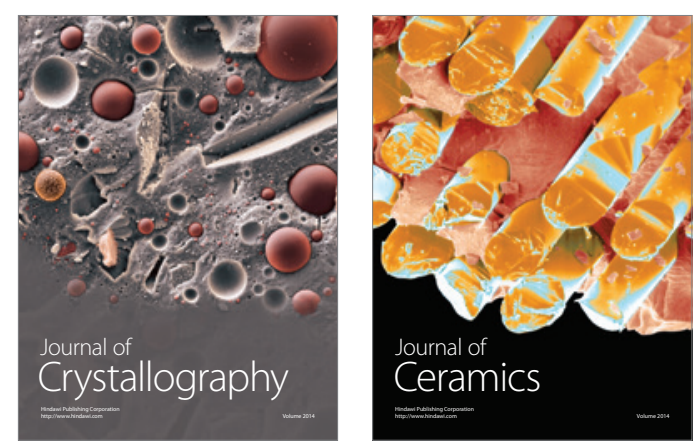
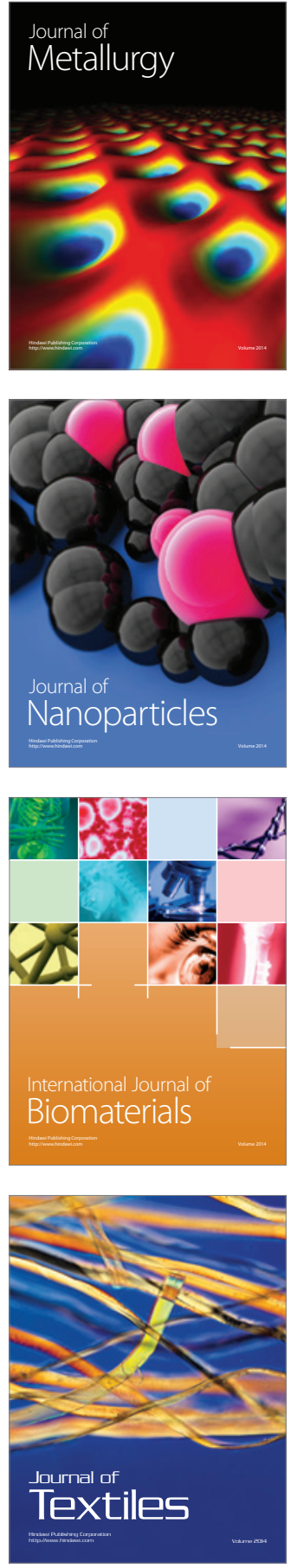